\title{
TRAFFIC CONFLICT IDENTIFICATION OF E-BIKES AT SIGNALIZED INTERSECTIONS
}

\author{
Zhaowei QU ${ }^{1}$, Yuhong $\mathrm{GAO}^{2}$, Xianmin $\mathrm{SONG}^{3 *}$, Yingji XIA ${ }^{4}$, Lin $\mathrm{MA}^{5}$, Ronghan $\mathrm{YAO}^{6}$ \\ ${ }^{1-5}$ School of Transportation, Jilin University, Changchun, China \\ ${ }^{6}$ School of Transportation and Logistics, Dalian University of Technology, Dalian, China
}

Submitted 25 January 2019; resubmitted 15 April 2019; accepted date 29 April 2019;

first published online 22 October 2020

\begin{abstract}
The increase of e-bikes has raised traffic conflict concerns over past decade. Numerous conflict indicators are applied to measure traffic conflicts by detecting differences in temporal or spatial proximity between users. However, for traffic environment with plenty of e-bikes, these separate space-time approaching indicators may not be applicable. Thus, this study aims to propose a multi-variable conflict indicator and build a conflict identification method for e-bikes moving in the same direction. In particular, by analysing the conflict characteristics from e-bikes trajectories, a multi-variable conflict indicator utilizing change of forecast post encroachment time, change of relative speed and change of distance is derived. Mathematical statistics and cluster discriminant analyses are applied to identify types of conflict, including conflict existence identification and conflict severity identification. The experimental results show: in mixed traffic environments with many e-bikes, compared with time-to-collision and deceleration, accuracy of identifying e-bike conflict types based on proposed method is the highest and can reach more than 90\%; that is, multi-variable indicator based on time and space are more suitable for identifying e-bike conflicts than separate space-time approaching indicators. Furthermore, setting of dividing strip between motor vehicle and non-motorized vehicle has significant influence on number and change trend of conflict types. The proposed method can not only provide a theoretical basis and technical support for automated conflict detection in mixed transportation, but also give the safety optimization sequence of e-bikes at different types of intersections.
\end{abstract}

Keywords: traffic safety, conflict identification, cluster discriminant analysis, e-bikes, trajectory extraction, signalized intersection.

\section{Notations}

$$
\begin{aligned}
& \text { ANOVA - analysis of variance; } \\
& \text { AUC - area under the ROC curve; } \\
& \text { BMV - bicycle - motor vehicle; } \\
& \text { CAS - collision avoidance system; } \\
& \text { FPET - forecast post encroachment time; } \\
& \text { MSDG - minimum safety distance gap; } \\
& \text { PDF - probability density function; } \\
& \text { PET - post encroachment time; } \\
& \text { ROC - receiver operating characteristic; } \\
& \text { TCT - traffic conflict technique; } \\
& \text { TET - time exposed TTC; } \\
& \text { TIT - time integrated TTC; } \\
& \text { TTA - time-to-accident; } \\
& \text { TTC - time-to-collision. }
\end{aligned}
$$

\section{Introduction}

E-bikes have been increasingly popular and become an important part of transportation system in many cities around the world. Unlike ordinary bike, e-bike has greater acceleration and speed, which may partly explain its rapid growth in recent years. Take China as an example, there were 200 million e-bikes in China by January 2018 (MIIT 2018). E-bike refers to a special bike with two wheels that operates on human (pedal) and battery-electric power. It constitutes a spectrum of designs from pedal style e-bike to scooter style e-bike. Both types of e-bikes have high travel speeds. Specifically, although the Safety Technical Specification for Electric Bicyle (MIIT 2018) stipulated that the maximum speed of e-bikes was $20 \mathrm{~km} / \mathrm{h}$, in the actual traffic environment, most pedal style e-bikes can run over $25 \mathrm{~km} / \mathrm{h}$ and the scooter-like ones can even reach over

${ }^{*}$ Corresponding author. E-mail: songxm@jlu.edu.cn 
$40 \mathrm{~km} / \mathrm{h}$. Obviously, increased mobility brings greater security risks. What followed is that mixed traffic conflicts have become increasingly prominent.

Traffic conflict is the interaction result of two participants or participants with facilities in the movement space. The traffic conflict identification method is a key component of traffic conflict technology. Therefore, it is necessary to study conflict indicators and conflict identification methods of e-bikes to improve road traffic safety.

At the First Workshop on Traffic Conflicts, the definition of traffic conflict was formally proposed as “... an observable situation in which two or more road users approach each other in space and time to such an extent that there is a risk of collision if their movements remain unchanged" (Amundsen 1977). Then, the TCT had arisen; it could efficiently evaluate the current situation of traffic safety and provide effective and safe improvement measures.

There are different conflict indicators for the traffic safety evaluation. From the aspect of difficulty of measuring indicators, time-based measures are easier because they are the result of combined effect for road users' speeds and distances. One of the most frequently used indicators is TTC. TTC is defined as "the time until a collision between the vehicles would occur if they continued on their present course at their present rates" (Hayward 1972). In the Swedish TCT, the TTC value at the start time of the evasive action (TTA) together with the travel speed are defined as an indicator of traffic conflict (Hyden 1987); while during the process of encounter, the minimum value of TTC $\left(\mathrm{TTC}_{\min }\right)$ is used as a part of the Dutch conflict observation technique; in many studies on the automatic identification of traffic conflicts (Autey et al. 2012; Sayed et al. 2013), $\mathrm{TTC}_{\min }$ has also been commonly used as a traffic conflict indicator.

TTC is applicable to identify a rear-end conflict; it reflects the time series that the vehicles reach at the potential conflict point. PET is another frequently used indicator applying to the angle conflict events. It is defined as the time between the first road user leaving the "conflict zone" and the second one arriving at it (Allen et al. 1978). However, for road users without conflict zone (such as bicycles), this type of conflict indicator is no longer applicable. In addition, although these indicators could describe the possibility of whether a conflict occurred, they cannot directly reflect the severity of the conflict.

Therefore, many researchers began to establish new conflict indicators to describe conflict severity. Sharizli et al. (2015) had promoted the MSDG to describe conflict severity. Laureshyn et al. (2017) extended the meaning of delta- $V$ and created the extended delta- $V$ indicator. Then, by utilizing the extended delta- $V$ conflict measure method, the proximity to a crash as well as the outcome severity in the event were integrated to determine severity of a traffic event. However, using single-variable judgement indicator could not reflect the overall safety performance of vehicles including crash probability and severity simultaneously.
As the study progresses, scholars have found that using different single-variable indicators for conflict identification sometimes produce opposite results (Saccomanno et al. 2008; Ismail et al. 2011). Thus, some researchers have started to establish integrated conflict indicators. Yang and Ozbay (2011) considered the vehicle confluence probability and collision probability, and proposed an integrated conflict indicator to evaluate the safety of converging section. Behbahani et al. (2014) combined TET with the TIT to apply in the CAS; the method reduced driving errors and rear-end collisions effectively. By utilizing the change in the total kinetic energy before and after the collision, angle of collision and PET, Alhajyaseen $(2014,2015)$ deduced a new conflict indicator; then, they proposed an overall safety measure considering accident probability as well as expected severity. Based on these analyses, researches on motor vehicle traffic conflict mainly focus on the establishment of single-variable indicator and the qualitative conflict type division, while there are fewer quantitative indicators with multi-variable that can simultaneously consider the effects of time and space.

With the popularity of bicycles, conflicts of mixed traffic flow are more prominent. Therefore, there is a big safety risk for the road traffic. The most familiar bicycle conflicts are the conflicts between right-turn vehicle and bicycle (Räsänen, Summala 1998); Kim et al. (2007) showed that speed was a key factor leading to bicyclevehicle conflicts or even traffic accidents. Therefore, the situation of traffic events can be improved by controlling speeds of vehicles. Minikel (2012) noted that fast speeds, high traffic and heavy vehicles were bad for riders, and these factors were more likely to lead to traffic conflicts. Wang and Nihan (2004) established the correlation between BMV accidents and traffic flows for different types, and proposed a method to estimate the BMV accident risk based on probability theory. Silvano et al. (2016) applied discrete selection theory to establish a probability model. The model could describe the interaction of bicycles and motor vehicles in the proximity of conflict areas. Based on the above analysis, in the process of conflict identification of mixed traffic flow, speed is the key factor affecting the conflict between vehicles, and the interaction between vehicles cannot be ignored.

With the increasing congestion of urban traffic, e-bikes are gradually replacing traditional bicycles with their flexible, economical and low-carbon features. Gradually they have become a more prevalent choice of the short-distance traveller. As a result, conflicts have become more prominent. It is shown, that pedestrians, vehicles and bicycles affect the travel safety of e-bikes (Dozza et al. 2016). Driving behaviours of non-motorized riders could vary according to the type of non-motorized vehicle. For example, e-bike cyclists are more likely to run through a red light than other types of cyclists at the crossroads (Langford et al. 2015; Pai, Jou 2014). Comparing the behaviour differences between e-bike cyclists and traditional cyclists, studies show that e-bikes cyclists would gain higher mobility at 
the expense of more risk behaviour (Bai et al. 2013; Cherry, Cervero 2007). Several scholars found that the factors causing behaviour differences are age, gender and stages of signal phase (Wu et al. 2012, 2016; Guo et al. 2014). $\mathrm{Xu}$ et al. (2016) identified the interrelationships of these factors and proposed a method to evaluate safety of nonmotorized lanes. At present, studies on e-bikes focus on characteristics of e-bikes and differences with traditional bicycles, and little research has been done on the increasingly serious e-bike conflicts problems. However, research on conflicts is important for control of mixed traffic flow, so this aspect is urgently needed.

Based on the above analysis, research on conflict indicators and identification method, which is applicable for special vehicles such as e-bikes is indispensable. In order to improve the safety of mixed-traffic flow at the intersection, this study proposes a multi-variable conflict indicator and describe a conflict identification method for e-bikes. Due to the complexity of mixed traffic, the paper only studies the conflict for e-bikes moving in the same direction at the separating vehicles and non-motorized vehicles signalized intersections.

To summarize, the research mainly has following two contributions:

"») utilizing change of FPET, change of relative speed and change of distance, a multi-variable conflict indicator suitable for describing conflict of e-bikes is proposed;

"»» mathematical statistics and cluster discriminant analyses are applied to identify types of conflict, including conflict existence identification and conflict severity identification.

The rest of paper is organized as follows: Section 1 gives collection and analysis of conflict data for e-bikes. Section 2 presents determination process of multi-variable conflict indicator and conflict identification method of ebikes. Section 3 compares identification results of different indicator and discusses experimental result of proposed method. The last section concludes the paper.

\section{Data description}

\subsection{Data collection}

In the actual traffic environment, the traffic flow of rightturn e-bike is small and there is basically no interference between e-bikes. So in this paper, we mainly study the e-bikes flow moving in through direction and left-turn direction. Specifically, we select the intersections according to following criteria:

"» having a separate non-motorized vehicle phase (or non-motorized vehicle phase lights in advance);

"» heavy e-bike traffic(the proportion of e-bike flow to total traffic at the intersection is greater than 0.3 );

"» few pedestrian and vehicle interference;

"» a variety of signalized intersection sizes;
"» effective traffic signs and markers;

"» an acceptable vantage point for the video recorder (around higher buildings, etc.).

Based on the above criteria, the data used in this study were collected from November 2015 to July 2017 by means of video cameras at six signalized intersections (Figure 1).

In this paper, video detection technology is used to track trajectories of e-bikes. Specifically: firstly, the e-bike is manually identified and labelled; then mean-shift algorithm is used for tracking and its motion trajectory in pixel coordinates of image is extracted; finally, the motion trajectory in pixel coordinates is converted into real trajectory in world coordinates by calibration. As a classical algorithm, mean-shift algorithm has been researched and improved by many scholars and its accuracy is high in theory (Ning et al. 2012); meanwhile e-bike can be approximated as a rigid body and the change itself is small during movement, which has less influence on accuracy of algorithm. In addition, in order to further verify the accuracy of algorithm, actual measured trajectory data is also used for verification and tracking accuracy can reach $93 \%$. This accuracy is considered reliable especially under heavy traffic flow conditions.

By video detection technology, trajectory information of e-bikes is obtained, including the temporal information and spatial location information. The average length of ebike is $1.5 \mathrm{~m}$, average speed is $5 \mathrm{~m} / \mathrm{s}$, so we define that the intercepting interval of video image is $0.3 \mathrm{~s}$. Finally, the survey obtains 2693 pairs of traffic flow and 59881 pairs of traffic flow trajectory points, including pixel coordinates, earth coordinates, instantaneous speed about e-bikes at different times. Through and left-turn e-bike traffic flow accounts for 64 and $36 \%$ respectively (Table 1 ).

\subsection{Data analysis}

\subsubsection{Influencing factors}

When e-bikes pass through signalized intersection, there are many factors that can cause traffic conflict. External factors are mainly geometric conditions of the intersection, surrounding building properties, traffic flow status, signal timing and so on. It is also closely related to internal factors such as: distance between e-bikes $L$, relative speed between e-bikes $V_{x d}$ and speed angle between e-bikes $\theta$. Hence an attempt has been made in this paper to analyse the temporal and spatial characteristics of $L, V_{x d}$ and $\theta$ as they provide theoretical support for the establishment of traffic conflict indicators.

The collection process of $L, V_{x d}$ and $\theta$ is as follows:

"') calculate the distance between e-bikes $L$ by using the real coordinate position of trajectory point in world coordinates;

"») e-bike speed is calculated by using the distance and time difference between continuous trajectory points;

"» use the speed to calculate relative speed between ebikes $V_{x d}$ and speed angle between e-bikes $\theta$. 

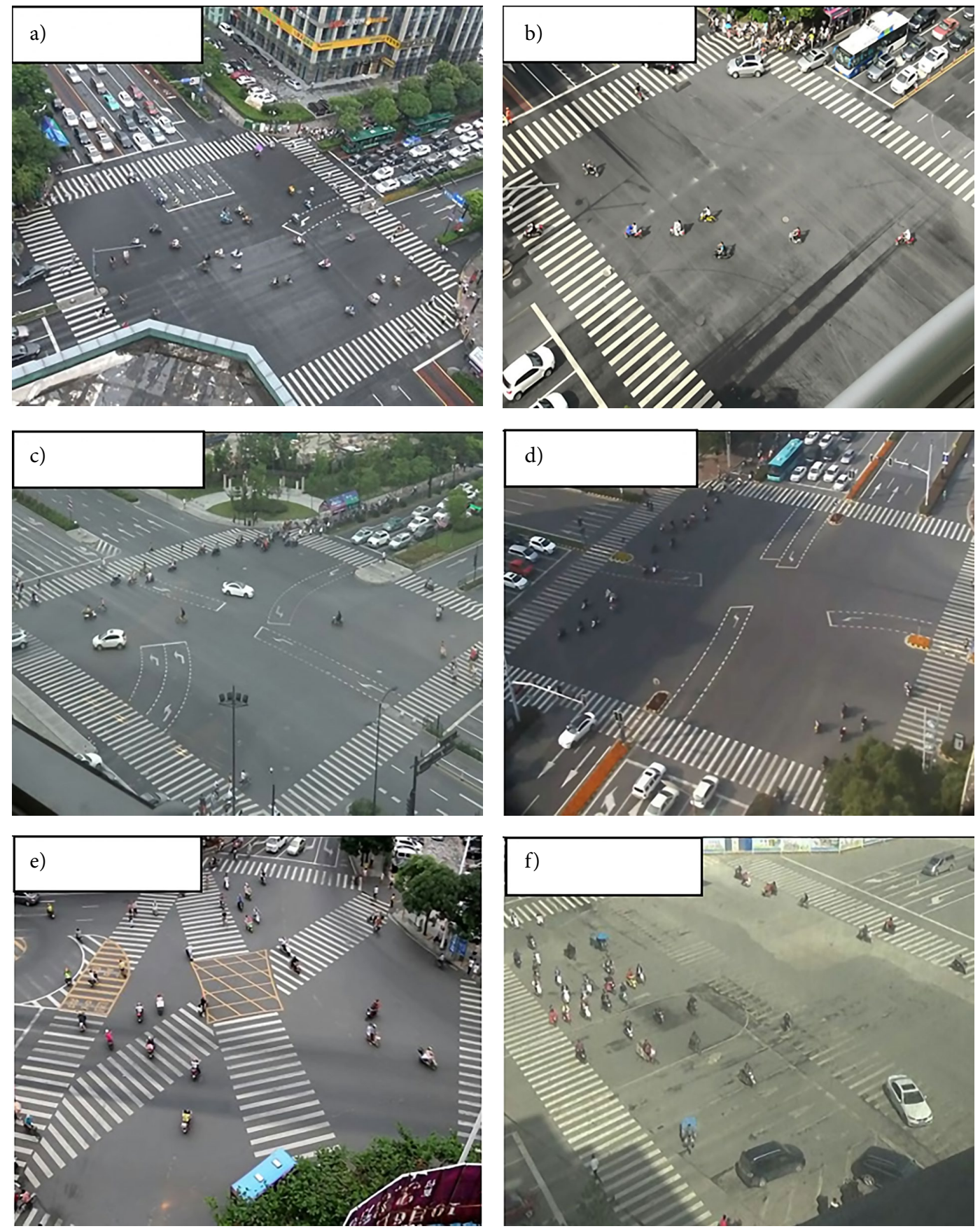

Figure 1. Field picture of signalized intersections: a - Location 1; b - Location 2; c - Location 3; $\mathrm{d}$ - Location 4; e - Location 5; f - Location 6

\subsubsection{Statistical characteristics}

In this part, the paper statistics characteristic differences among $L, V_{x d}$ and $\theta$. First, data is divided at a statistical interval of $0.45 \mathrm{~m}$ - the value is width of e-bike that is quoted from MIIT (2018); then we calculate the average of all $V_{x d}$ and $\theta$ within each interval length respectively; finally, change graphs of average value obtained in different directions are drawn (Figure 2).

Figure 2 shows that relationships among $L, V_{x d}$ and $\theta$ have differences in various directions. When $L<11.25 \mathrm{~m}$, $V_{x d}$ and $\theta$ of through e-bikes remain stable; otherwise, $V_{x d}$ and $\theta$ will change dramatically. Therefore, the paper defines that $11.25 \mathrm{~m}$ is the state change point between through e-bikes. Similarly, motion change point of leftturn e-bikes is $9.45 \mathrm{~m}$. The difference in the value of state change point may be due to following reasons. In surveyed videos, through traffic flow is denser than left-turn. Therefore, the distance between through e-bikes is small, and speed and direction of e-bikes are not easy to change. As a result, through e-bikes need to travel a long distance to increase driving space to change state of motion. In addition, when left-turn e-bikes are closer to exit, they will change directions and cut into non-motorized vehicle lane. Thereby the distance between e-bikes is shortened. 
Table 1. The parameter characteristics of observation location

\begin{tabular}{|c|c|c|c|c|c|c|c|}
\hline $\begin{array}{l}\text { Location } \\
\text { number }\end{array}$ & $\begin{array}{l}\text { Observation } \\
\text { location }\end{array}$ & $\begin{array}{c}\text { Intersection } \\
\text { size } \\
{[\mathrm{m} \times \mathrm{m}]} \\
\end{array}$ & $\begin{array}{l}\text { Survey time } \\
\text { period }\end{array}$ & $\begin{array}{l}\text { Non-motorized } \\
\text { vehicle phase }\end{array}$ & $\begin{array}{c}\text { Travel } \\
\text { direction } \\
\text { of e-bikes } \\
\end{array}$ & $\begin{array}{c}\text { Pairs } \\
\text { of traffic } \\
\text { flow }\end{array}$ & \begin{tabular}{|c|} 
Pairs \\
of trajectory \\
points
\end{tabular} \\
\hline \multirow{2}{*}{ Location 1} & \multirow{2}{*}{$\begin{array}{l}\text { Jiao Gong Road - Wen } \\
\text { Yi Road intersection in } \\
\text { Hangzhou City, Zhejiang } \\
\text { Province }\end{array}$} & \multirow{2}{*}{$38 \times 40$} & \multirow{2}{*}{$\begin{array}{c}3 \text { July } 2017 \\
16: 30 \ldots 20: 00\end{array}$} & \multirow{2}{*}{ separated } & $\begin{array}{l}\text { through - } \\
\text { through }\end{array}$ & 454 & 8931 \\
\hline & & & & & $\begin{array}{l}\text { left-turn - } \\
\text { left-turn }\end{array}$ & 209 & 7958 \\
\hline \multirow{2}{*}{ Location 2} & \multirow{2}{*}{$\begin{array}{l}\text { Wen San Road - Gu } \\
\text { Cui Road intersection in } \\
\text { Hangzhou City, Zhejiang } \\
\text { Province }\end{array}$} & \multirow{2}{*}{$36 \times 40$} & \multirow{2}{*}{$\begin{array}{c}30 \text { June } 2017 \\
6.30 \ldots 7.30\end{array}$} & \multirow{2}{*}{$\begin{array}{l}\text { lights in } \\
\text { advance }\end{array}$} & $\begin{array}{l}\text { through - } \\
\text { through }\end{array}$ & 574 & 10778 \\
\hline & & & & & $\begin{array}{l}\text { left-turn - } \\
\text { left-turn }\end{array}$ & 393 & 8004 \\
\hline \multirow{2}{*}{ Location 3} & \multirow{2}{*}{$\begin{array}{l}\text { Yu Hang Tang Road - Gu } \\
\text { Dun Road intersection in } \\
\text { Hangzhou City, Zhejiang } \\
\text { Province }\end{array}$} & \multirow{2}{*}{$41 \times 42$} & \multirow{2}{*}{$\begin{array}{l}30 \text { June } 2017 \\
17: 00 \ldots 19: 00\end{array}$} & \multirow{2}{*}{$\begin{array}{l}\text { lights in } \\
\text { advance }\end{array}$} & $\begin{array}{l}\text { through - } \\
\text { through }\end{array}$ & 398 & 10875 \\
\hline & & & & & $\begin{array}{l}\text { left-turn - } \\
\text { left-turn }\end{array}$ & 130 & 3196 \\
\hline \multirow{2}{*}{ Location 4} & \multirow{2}{*}{$\begin{array}{l}\text { Xing Ming Street - Modern } \\
\text { Avenue intersection in } \\
\text { Suzhou City, Jiangsu } \\
\text { Province }\end{array}$} & \multirow{2}{*}{$50 \times 56$} & \multirow{2}{*}{$\begin{array}{c}3 \text { November } 2015 \\
8: 40 \ldots 9: 10\end{array}$} & \multirow{2}{*}{$\begin{array}{l}\text { lights in } \\
\text { advance }\end{array}$} & $\begin{array}{l}\text { through - } \\
\text { through }\end{array}$ & 35 & 540 \\
\hline & & & & & $\begin{array}{l}\text { left-turn - } \\
\text { left-turn }\end{array}$ & 17 & 475 \\
\hline \multirow{2}{*}{ Location 5} & \multirow{2}{*}{$\begin{array}{l}\text { Yue Jin Road - Zhong Shan } \\
\text { Yi Road -Wu Yi Road } \\
\text { intersection in Zhanjiang } \\
\text { City, Guangdong Province }\end{array}$} & \multirow{2}{*}{$44 \times 40$} & \multirow{2}{*}{$\begin{array}{c}1 \text { November } 2016 \\
16: 40 \ldots 17: 40\end{array}$} & \multirow{2}{*}{ separated } & $\begin{array}{l}\text { through - } \\
\text { through }\end{array}$ & 50 & 854 \\
\hline & & & & & $\begin{array}{l}\text { left-turn - } \\
\text { left-turn }\end{array}$ & 63 & 1251 \\
\hline \multirow{2}{*}{ Location 6} & \multirow{2}{*}{\begin{tabular}{|l|} 
Shang Du Road - Huang \\
He South Road intersection \\
in Zhengzhou City, Henan \\
Province
\end{tabular}} & \multirow{2}{*}{$36 \times 46$} & \multirow{2}{*}{$\begin{array}{l}18 \text { April } 2017 \\
9: 10 \ldots 10: 40\end{array}$} & \multirow{2}{*}{$\begin{array}{l}\text { lights in } \\
\text { advance }\end{array}$} & $\begin{array}{l}\text { through - } \\
\text { through }\end{array}$ & 213 & 3408 \\
\hline & & & & & $\begin{array}{l}\text { left-turn - } \\
\text { left-turn }\end{array}$ & 157 & 3611 \\
\hline & & & & & Total & 2693 & 59881 \\
\hline
\end{tabular}
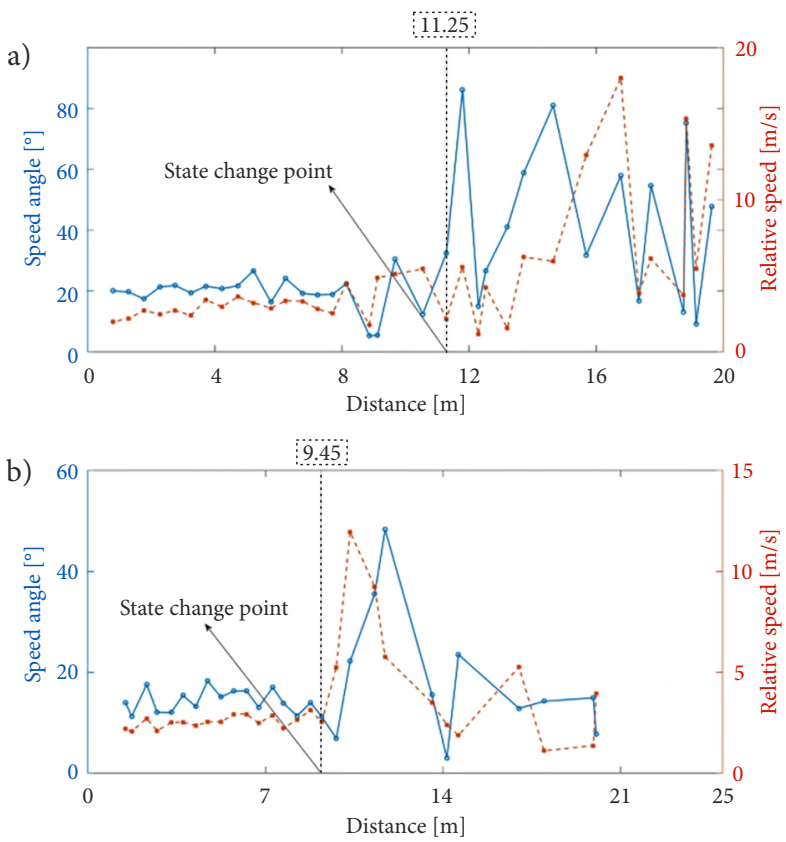

Figure 2. The impact of e-bikes conflict factors: a - the relationship of through e-bikes among $L, V_{x d}$ and $\theta$; $\mathrm{b}$ - the relationship of left-turn e-bikes among $L, V_{x d}$ and $\theta$

From the above analysis, it can be seen that changes in $L, V_{x d}$ and $\theta$ can reflect changes of e-bikes motion state. Therefore, if multiple variables are used at the same time, it is more likely to reflect the degree of conflict between e-bikes and discrimination effect may be better.

\section{Methodology}

The methodology of conflict identification consists of two steps:

"») determination of multi-variable conflict indicator based on data analysis;

"») proposing an identification method of conflict types based on mathematical statistical and cluster discriminant analysis.

The details of each step are provided in the following sections.

\subsection{Determination of multi-variable conflict indicator}

Previous studies have applied numerous conflict indictors, such as TTC, PET and so on. But they are not suitable for the discrimination between e-bikes. For example, TTC is applicable to identify a rear-end conflict, but there are cross conflict or interference between e-bikes; PET is frequently used for angle conflict events but it is necessary to determine conflict zone. However, e-bike is small in size and specific zone cannot be specified. Therefore, for special vehicle like e-bike, a new indictor is needed to distinguish conflict types.

In order to find an indicator suitable for judging the conflict between e-bikes, the paper describes the movement of e-bikes during left-turn phase at one intersection (Figure 3). At moment $i(i=t, t+1)$, the space position of red e-bike and blue e-bike is $P_{A}(i)$ and $P_{B}(i)$ respectively; 
the corresponding speeds of two e-bikes are $V_{A}(i)$ and $V_{B}(i) ; L_{A}(i)$ is the distance between $P_{A}(i)$ and potential conflict point $O_{i} ; L_{B}(i)$ is the distance between $P_{B}(i)$ and $O_{i} ; L_{A B}(i)$ is the distance between $P_{A}(i)$ and $P_{B}(i)$. In addition, $\varphi_{A}$ is the speed angle of red e-bike from $P_{A}(t)$ to $P_{A}(t+1) ; \varphi_{B}$ is the speed angle of blue e-bike from $P_{B}(t)$ to $P_{B}(t+1)$.

Combined with the change characteristics of e-bike motion state (speed, distance) in Figure 3, a new variable FPET is defined firstly. If two vehicles maintain the current speed and driving direction at moment $i$, FPET is the expected time difference that these two vehicles arrive at the potential conflict point $O_{i}$. The calculation formula of FPET is:

$$
\operatorname{FPET}_{A B}(i)=\left|\frac{L_{A}(i)}{V_{A}(i)}-\frac{L_{B}(i)}{V_{B}(i)}\right| .
$$

Based on analysis results of Section 1.2.2 and state description of conflict traffic flow in Figure 3, it can be found that utilizing change of forecast post encroachment time between e-bikes $\triangle F P E T$, change of distance between e-bikes $\Delta L$ and change of relative speed between e-bikes $\Delta V_{x d}$ comprehensively can more fully reflect state change of e-bikes. Further, according to summary of introduction section, using single-variable judgement indicator could not reflect the overall safety performance of vehicles. Thus, this paper chooses $\triangle F P E T, \Delta L$ and $\Delta V_{x d}$ as key variables, and the multi-variable conflict indicator is derived.

Among them, the calculation process of key variables is as follows:

"» calculate the speed of e-bike and the distance between e-bikes by using the real coordinate position of trajectory point in world coordinates;

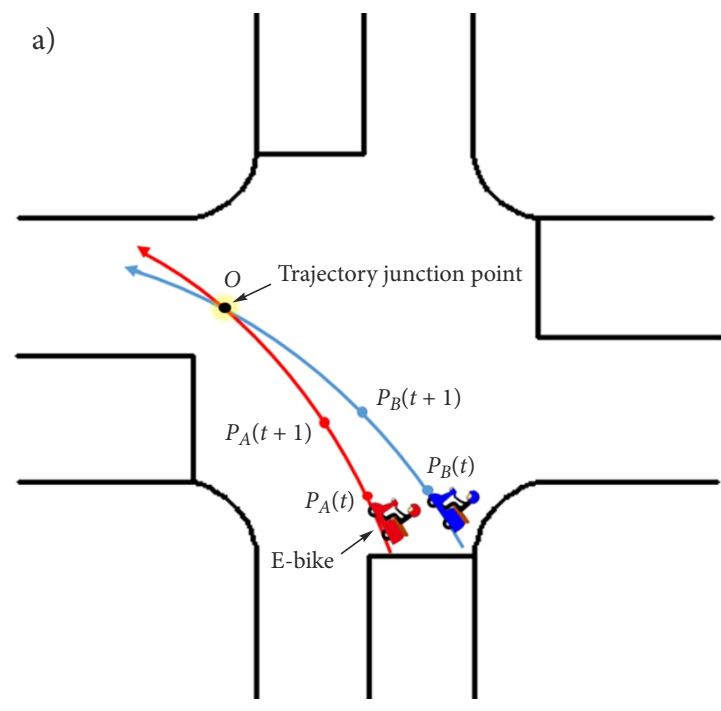

"»" calculate the relative speed and change value between e-bikes, and change value of distance between e-bikes;

"» using FPET calculation formula (Equation 1), FPET and its change value are obtained by speed and distance between e-bikes.

\subsection{Identification method of conflict types}

According to actual traffic data, the conflicts in this paper are divided into three types: non-conflict, non-serious conflict and serious conflict. Therefore, the establishment of conflict identification method includes two steps: The first step is the conflict existence identification, namely the identification of non-conflict and conflict; the second step is the conflict severity identification, namely the identification of non-serious conflict and serious conflict. This part mainly utilizes the data of Location 1 through Location 3 for analysis. The specific process shown in Figure 4.

\subsubsection{Conflict existence identification}

\section{Cluster analysis}

This paper uses the $K$-means clustering method to identify conflict existence. The $\triangle F P E T, \Delta L$ and $\Delta V_{x d}$ are the clustering variables. First, combined with inconsistency coefficient, the optimal classification of data is automatically identified as two types. Then, due to large amount of clustering data (59881 pairs trajectory points), we use $K$ means clustering method to demarcate the conflict types of two types. The clustering results are shown in Table 2.

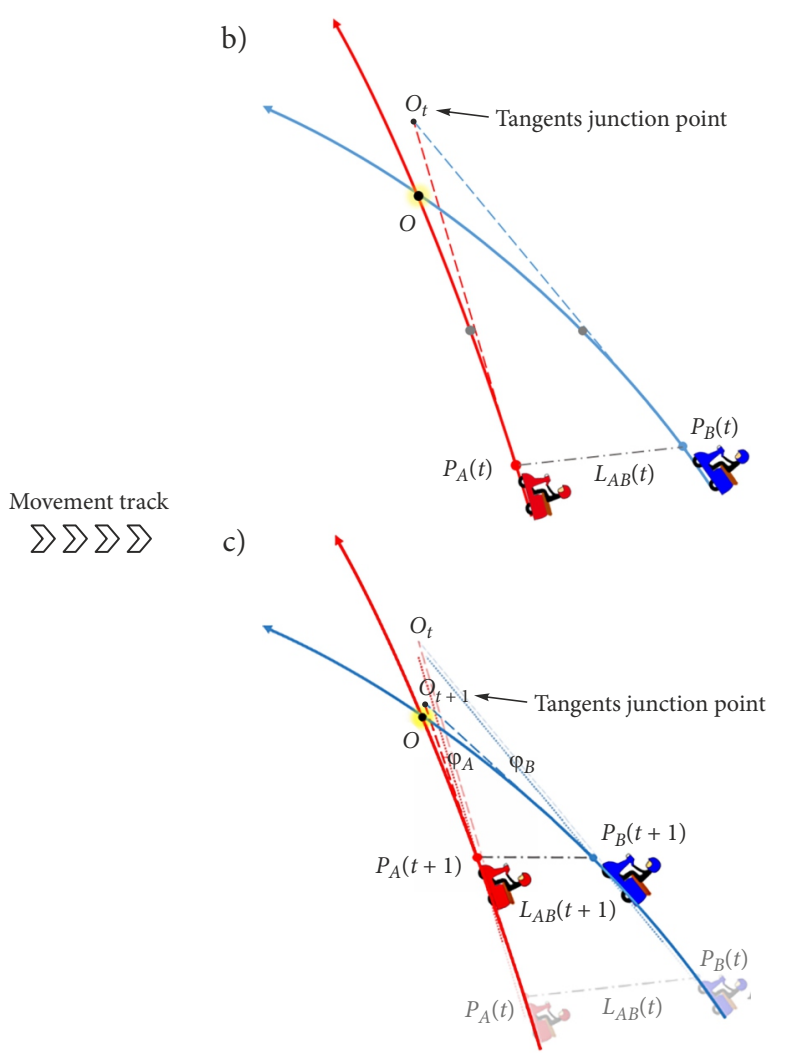

Figure 3. Moving process of the e-bikes at signalized intersection: a - the trajectories of e-bikes; $\mathrm{b}-$ motion states of e-bikes at moment $t$; $\mathrm{c}-$ motion states of e-bikes at moment $t+1$ 


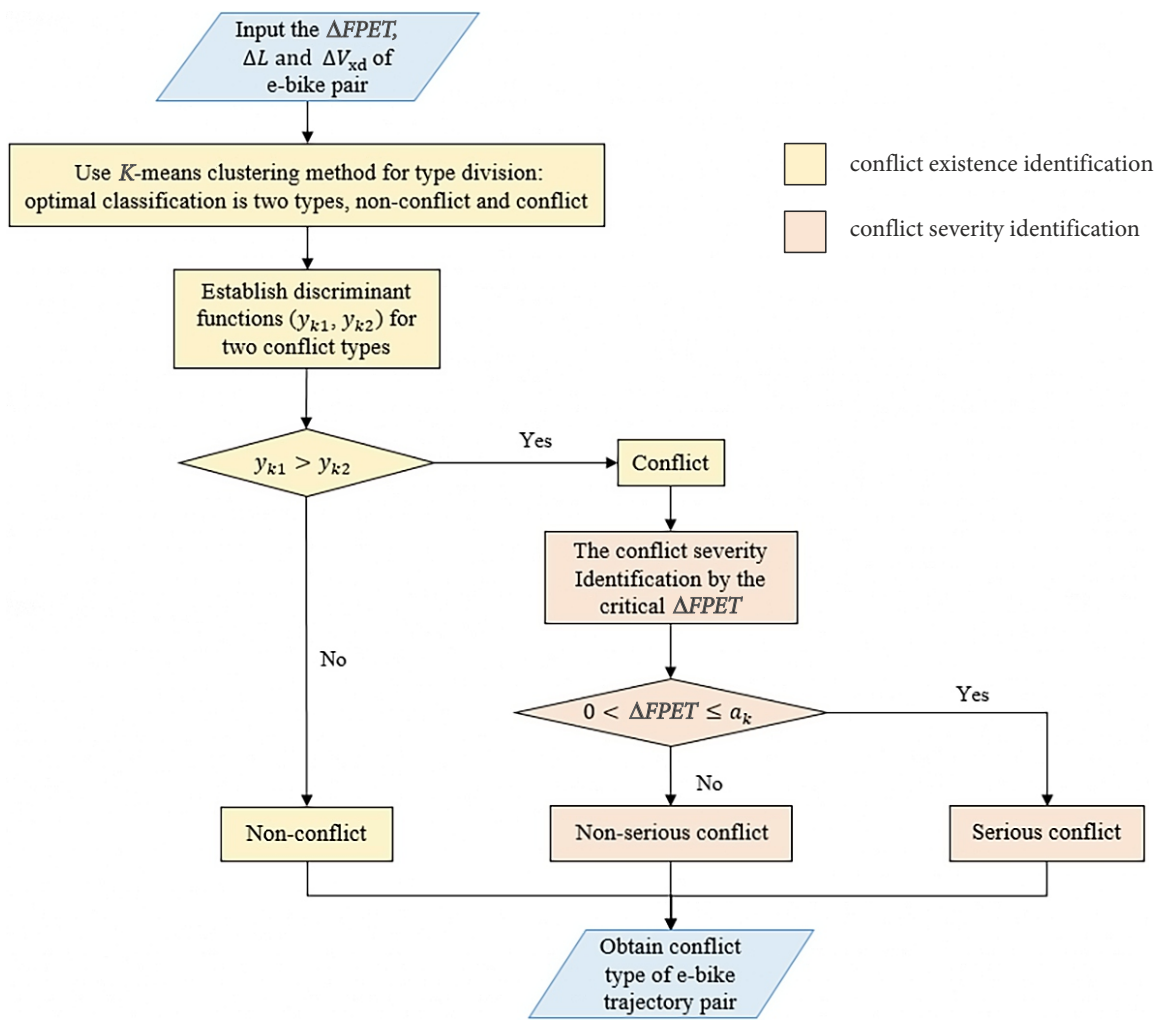

Figure 4. Discrimination process of e-bike conflict types ( $a_{k}-$ marginal value of serious conflict in $k$ directions)

Table 2. Clustering results of variables

\begin{tabular}{|c|c|c|c|c|}
\hline \multicolumn{5}{|c|}{ Through - through e-bikes } \\
\hline \multicolumn{2}{|c|}{$K$-means clustering method } & $\triangle F P E T[\mathrm{~s}]$ & $\Delta L[\mathrm{~m}]$ & $\Delta V_{x d}[\mathrm{~m} / \mathrm{s}]$ \\
\hline \multirow[t]{3}{*}{ The first type } & mean & 0.8819 & 0.6221 & 4.2808 \\
\hline & pairs of trajectory points & 7662 & 7662 & 7662 \\
\hline & standard deviation & 2.9616 & 0.4955 & 2.0223 \\
\hline \multirow[t]{3}{*}{ The second type } & mean & 2.4946 & 0.3839 & 1.2373 \\
\hline & pairs of trajectory points & 22922 & 22922 & 22922 \\
\hline & standard deviation & 1.0725 & 0.2953 & 0.8600 \\
\hline \multicolumn{5}{|c|}{ Left-turn - left-turn e-bikes } \\
\hline \multicolumn{2}{|c|}{$K$-means clustering method } & $\triangle F P E T[\mathrm{~s}]$ & $\Delta L[\mathrm{~m}]$ & $\Delta V_{x d}[\mathrm{~m} / \mathrm{s}]$ \\
\hline \multirow[t]{3}{*}{ The first type } & mean & 0.7858 & 0.4418 & 2.1544 \\
\hline & pairs of trajectory points & 4883 & 4883 & 4883 \\
\hline & standard deviation & 1.4894 & 0.3800 & 1.7360 \\
\hline \multirow[t]{3}{*}{ The second type } & mean & 4.3073 & 0.4027 & 1.8180 \\
\hline & pairs of trajectory points & 14275 & 14275 & 14275 \\
\hline & standard deviation & 0.6321 & 0.3459 & 1.5067 \\
\hline
\end{tabular}

When conflict is going to occur, drivers will make some measures of avoidance, such as deceleration, braking etc. At that time, $\Delta L$ and $\Delta V_{x d}$ will increase obviously, $\triangle F P E T$ will become obviously smaller. Corresponding to the data in Table 2, it can be seen that the first type is type of conflict and the second type is non-conflict. Besides, one-way ANOVA shows that significance of three vari- ables is less than 0.05 . In other words, all three variables contribute to clustering.

As shown in Table 2, motion states of e-bikes have significant differences in two conflict types. In addition, comparing values of three parameters, it is found that through e-bikes change their motion states more quickly for avoiding road users. 


\section{Discriminant analysis}

In order to part conflict types dynamically, paper uses the method of enter independent together to build the Fisher linear discriminant functions. At the same time, the Wilk test is necessary for discriminant functions. The test results show that their significance is less than 0.05; that is, the established linear discriminant functions can distinguish two types of samples effectively and have a strong statistical significance. The Fisher linear discriminant functions are:

$$
\begin{aligned}
& y_{k 1}=b_{1} \cdot \Delta F P E T+b_{2} \cdot \Delta L+b_{3} \cdot \Delta V_{x d}+b_{4} ; \\
& y_{k 2}=c_{1} \cdot \Delta F P E T+c_{2} \cdot \Delta L+c_{3} \cdot \Delta V_{x d}+c_{4},
\end{aligned}
$$

where: $k$ - travel direction of e-bike ( $k=1$ represents through e-bike, $k=2$ represents left turn e-bike); $y_{k 1}-$ discriminant function 1 of different conflict types in $k$ direction; $y_{k 2}$ - discriminant function 2 of different conflict types in $k$ direction; $b_{j}$ - undetermined parameters, their specific values are based on actual data $(j=1,2,3,4) ; c_{j}-$ undetermined parameters, their specific values are based on actual data $(j=1,2,3,4)$.

If $y_{k 1}>y_{k 2}$, it indicates that the sample belongs to the type of conflict, otherwise sample belongs to the type of non-conflict.

In addition, the paper verifies the performance of discriminant functions by cross validation, and the results show that cross validation can classify $98 \%$ of the samples correctly. So far, the discriminant equations for conflict existence have been established.

\subsubsection{Conflict severity identification}

To further classify the severity of conflict, this paper has conducted an in-depth analysis of conflict type data. It is found that there is always a break point for $\triangle F P E T$, $\Delta L$ and $\Delta V_{x d}$ in each group of conflict trajectories at the same moment, as is shown by number 12 in Figure 5 . The $\triangle F P E T$ corresponding to break point is defined as critical $\triangle F P E T$ in the paper. Consequently, the critical $\triangle F P E T$ is used as the indicator of conflict severity identification.

After determining critical $\triangle F P E T$ as the indicator to judge the severity of conflict, it is necessary to further analyse the numerical characteristics of it (Table 3 ).

Combined with the operation regularity of e-bike and definition of FPET, discriminant value (critical $\triangle F P E T$ ) of conflict severity should be within the range of mean value of conflict type. As shown in Tables 2 and 3, so the mean of critical $\triangle F P E T$ is chosen as marginal value of serious conflict. Then threshold intervals for different conflict types can be determined. Specifically, when the result of discriminant analysis is type of conflict and value of $\triangle F P E T$

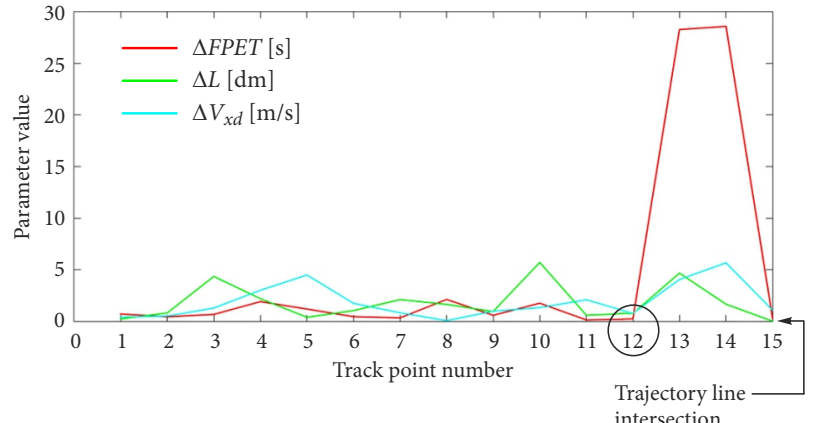

Figure 5. Schematic diagram for determining indicator of conflict severity

for through e-bikes is between 0 and $0.5862 \mathrm{~s}$, then the type of conflict is a serious conflict. Otherwise, the type is non-serious conflict. Similarly, if its type is conflict and value of $\triangle F P E T$ for left-turn e-bikes is between 0 and $0.7613 \mathrm{~s}$, then the type of conflict is a serious conflict; otherwise, it is the non-serious conflict. So far, conflict type identification method for e-bikes has been completed.

\section{Results and discussion}

\subsection{Method validation}

To verify the effectiveness of method, we tested the conflict types with field data of Location 4 through Location 6. The parameter characteristics of locations are shown in Table 1 . The validation mainly includes establishment of test standards and comparative analysis of test results.

\subsubsection{Establishment of test standards}

To verify correctness of proposed method, the paper selects two types of videos that can directly distinguish types of conflicts for analysis: one is the video of e-bikes with obvious serious conflicts (such as the behaviour of e-bike being forced to stop); the other is the video of e-bikes running freely, which its traffic volume is small and there is no interference between e-bikes obviously. Because change of relative speed between e-bikes $\Delta V_{x d}$ and change of speed angle between e-bikes $\Delta \theta$ can reflect change of distance and travel direction between e-bikes, these two types of data in condition of serious conflict and non-conflict are collected respectively. Then the distribution characteristics of $\Delta V_{x d}$ and $\Delta \theta$ are drawn. The results show that $\Delta V_{x d}$ and $\Delta \theta$ are normally distributed in different motion states (Figure 6). The PDF is:

$$
f(x)=\frac{1}{\sqrt{2 \cdot \pi \cdot \sigma}} \cdot e^{-\frac{(x-\mu)^{2}}{2 \cdot \sigma^{2}}}, x>0,
$$

\begin{tabular}{|c|c|c|c|c|c|c|c|c|}
\hline $\begin{array}{l}\text { Travel direction } \\
\text { of e-bikes }\end{array}$ & $\begin{array}{c}\text { Pairs of } \\
\text { trajectory points }\end{array}$ & $\underset{[\mathrm{s}]}{\operatorname{Minimum}}$ & $\underset{[s]}{\operatorname{Maximum}}$ & $\begin{array}{l}\text { Mean } \\
{[\mathrm{s}]}\end{array}$ & $\begin{array}{c}\text { Standard deviation } \\
{[\mathrm{s}]}\end{array}$ & Variance & Skewness & Kurtosis \\
\hline Through - through & 1267 & 0.0002 & 13.3039 & 0.5862 & 1.0575 & 1.1184 & 6.0564 & 52.8170 \\
\hline Left-turn - left-turn & 663 & 0.0003 & 9.9595 & 0.7613 & 1.2560 & 1.5780 & 3.6950 & 16.9071 \\
\hline
\end{tabular}

Table 3. Critical $\triangle F P E T$ statistics table 
where: $x$ - value of $\Delta V_{x d}$ and $\Delta \theta$ for different conflict types; $f(x)$ - PDF; $\mu$ - mean of variable $x ; \sigma$ - standard deviation of variable $x$.

According to the $3 \cdot \sigma$ criterion, study chooses $\mu \pm \sigma$ as the standard range to identify non-conflict and serious conflict. When the standard ranges of $\Delta V_{x d}$ and $\Delta \theta$ belong to non-conflict (serious conflict) at the same time, the type of trajectory pair is non-conflict (serious conflict); otherwise, it belongs to non-serious conflict. As shown in Table 4.

So far, establishment of test standards has been completed. In the actual test, accuracy of model can be verified by comparing it with proposed method. While Table 4 is only used as the test standards in this paper.

\subsubsection{Comparative analysis of test results}

According to Figure 4, we provide a group data of left-turn e-bikes as an example to illustrate the test process. Specific steps are as follows:

"» Step 1: Obtain the $\triangle F P E T, \Delta L$ and $\Delta V_{x d}$ of left-turn e-bikes;

»» Step 2: Substituting $\triangle F P E T, \Delta L$ and $\Delta V_{x d}$ into Fisher linear discriminant functions - Equations (2) and (3).

a)

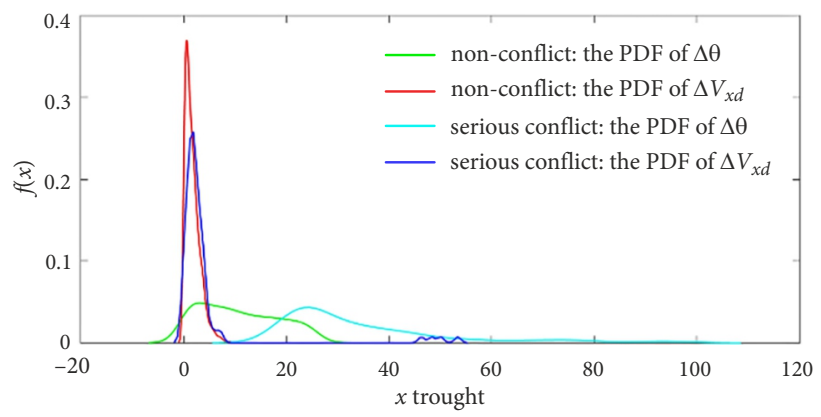

b)

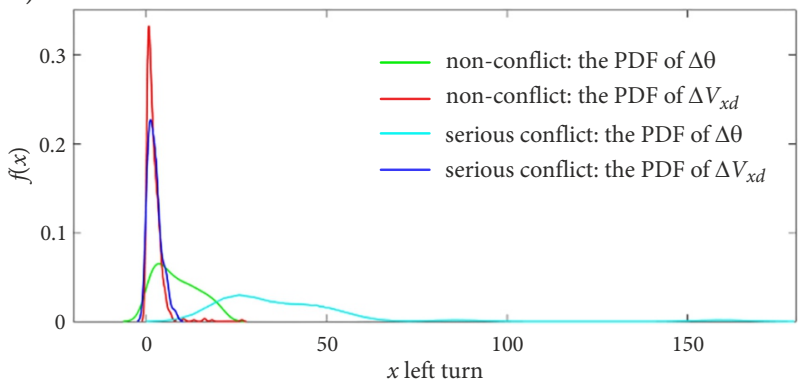

Figure 6. Distribution function of $\Delta V_{x d}$ and $\Delta \theta$ under different motion states: $\mathrm{a}$ - through e-bikes; $\mathrm{b}$ - left-turn e-bikes
In this test, specific parameter values of Equations (2) and (3) are as follows: $k=2, b_{1}=-0.006, b_{2}=3.674$, $b_{3}=4.062, b_{4}=-12.774, c_{1}=0.01, c_{2}=2.324, c_{3}=$ $1.042, c_{4}=-1.331$. So if $y_{k 1}>y_{k 2}$, it belongs to type of conflict, otherwise sample belongs to type of nonconflict. It should be noted here that the clustering part has been completed when the method is proposed, so there is no need to repeat in actual use; "» Step 3: Further identify the severity of conflict. In this test, $k=2$ and $a_{2}=0.7613$. So if $\triangle F P E T$ is between 0 and $0.7613 \mathrm{~s}$, then the type is a serious conflict; otherwise, it is the non-serious conflict;

") Step 4: Verify the identification results. Compare the identification results by test standards with results by proposed method, accuracy of method can be obtained.

The final test results are shown in Table 5.

According to the test process of above example, test results of all locations are obtained (Figure 7): here, Location 4 and Location 5 are the intersections, which have dividing strips between motor vehicle lanes and non-motorized vehicle lanes, while location 6 has no dividing strip.

It can be seen from Figure 7 that proposed method has a high accuracy overall. Furthermore, setting of dividing strip has a certain influence on the trend of conflicts number: overall trend is that as the severity of conflict increases, number of conflict gradually decreases, but no dividing strip will rise slightly at the end. In addition, there are significant differences in the number of conflicts between through and left-turn directions, which is related to environmental differences at intersections. Therefore, in practical applications, it is possible to compare e-bike conflicts in different directions and intersection types. Then, the basis for safe optimization sequence of e-bikes is determined.

In order to further test proposed method in this paper, a comparison was made with TTC and deceleration. Typically, road safety analysts will study conflict events with TTC less than $3 \mathrm{~s}$; meantime $1.5 \mathrm{~s}$ TTC threshold is usually associated with serious conflicts (Tageldin et al. 2015). Therefore, the paper utilizes 3 and $1.5 \mathrm{~s}$ respectively as threshold to distinguish conflict types. In addition, deceleration mean of different experts categorization is used as threshold for different conflict types, specifically 1.5 and $4 \mathrm{~m} / \mathrm{s}^{2}$ (Tageldin et al. 2015). Results are shown in Table 6 and Figure 8.

Table 6 and Figure 8 show - compared with TTC and deceleration, accuracy of proposed method is the highest, both above $90 \%$; deceleration is more accurate than TTC.

Table 4. Statistical Value of $\Delta V_{x d}$ and $\Delta \theta$ under different conflict types

\begin{tabular}{|c|l|c|c|c|c|c|c|c|}
\hline \multirow{2}{*}{ Travel direction } & \multirow{2}{*}{ Conflict types } & \multirow{2}{*}{ Pairs of trajectory points } & \multicolumn{2}{|c|}{$\Delta V_{x d}[\mathrm{~m} / \mathrm{s}]$} & \multicolumn{3}{|c|}{$\left.\Delta \theta{ }^{\circ}\right]$} \\
\cline { 4 - 9 } & & & $\mathrm{m}$ & $\mathrm{s}$ & $\mu \pm \sigma$ & $\mathrm{m}$ & $\mathrm{s}$ & $\mu \pm \sigma$ \\
\hline \multirow{2}{*}{ Through - through } & non-conflict & 1996 & 1.74 & 1.45 & $(0.29,3.19)$ & 10.78 & 7.59 & $(3.19,18.37)$ \\
\cline { 2 - 9 } & serious conflict & 131 & 4.20 & 9.74 & $(0,13.94)$ & 36.29 & 16.44 & $(19.85,52.73)$ \\
\hline \multirow{2}{*}{ Left-turn - left-turn } & non-conflict & 850 & 2.13 & 2.20 & $(0,4.33)$ & 8.59 & 5.97 & $(2.62,14.56)$ \\
\cline { 2 - 9 } & serious conflict & 124 & 2.38 & 1.82 & $(0.56,4.2)$ & 38.11 & 23.26 & $(14.85,61.37)$ \\
\hline
\end{tabular}


Table 5. The test results of a group of left-turn e-bikes

\begin{tabular}{|c|c|c|c|c|c|c|c|c|}
\hline $\begin{array}{c}\text { Track point } \\
\text { sequence }\end{array}$ & $\triangle F P E T[\mathrm{~s}]$ & $\Delta L[\mathrm{~m}]$ & $\Delta V_{x d}[\mathrm{~m} / \mathrm{s}]$ & $\Delta \theta\left[^{\circ}\right]$ & $y_{21}$ & $y_{22}$ & $\begin{array}{l}\text { Predicted } \\
\text { conflict type }\end{array}$ & Actual conflict type \\
\hline 1 & 0.4812 & 0.5197 & 3.1924 & 13.5465 & 2.0740 & 3.2081 & non-conflict & non-conflict \\
\hline 2 & 1.4510 & 0.4937 & 3.5806 & 3.8921 & 3.4972 & 3.5619 & non-conflict & non-conflict \\
\hline 3 & 2.9825 & 0.2857 & 5.6656 & 49.9054 & 11.1104 & 5.2663 & non-serious conflict & non-serious conflict \\
\hline 4 & 0.2427 & 0.3811 & 0.9997 & 13.3138 & -7.3276 & 0.5988 & non-conflict & non-conflict \\
\hline 5 & 0.5645 & 0.5466 & 0.2230 & 12.9462 & -9.8938 & 0.1773 & non-conflict & non-conflict \\
\hline 6 & 0.6214 & 1.4168 & 1.9296 & 8.1830 & 0.2321 & 3.9785 & non-conflict & non-conflict \\
\hline 7 & 2.4899 & 0.8833 & 3.6439 & 14.7310 & 5.1234 & 4.5436 & non-serious conflict & non-serious conflict \\
\hline 8 & 0.9514 & 1.1533 & 2.6529 & 12.3957 & 2.1822 & 4.1231 & non-conflict & non-conflict \\
\hline 9 & 0.7599 & 0.9083 & 3.8657 & 14.6731 & 6.2200 & 4.8155 & serious conflict & non-serious conflict \\
\hline 10 & 0.6584 & 0.4669 & 1.3376 & 6.0378 & -5.6648 & 1.1544 & non-conflict & non-conflict \\
\hline 11 & 0.9551 & 1.8937 & 1.5806 & 4.6721 & 0.5464 & 4.7264 & non-conflict & non-conflict \\
\hline 12 & 0.5645 & 1.5466 & 3.2230 & 24.7462 & 5.9665 & 5.6274 & serious conflict & serious conflict \\
\hline 13 & 0.7514 & 1.4168 & 3.9296 & 58.1830 & 8.3484 & 6.0638 & serious conflict & serious conflict \\
\hline 14 & 3.1774 & 0.2083 & 6.1997 & 14.6831 & 12.9839 & 5.6450 & non-serious conflict & non-serious conflict \\
\hline 15 & 1.6584 & 0.4669 & 1.3376 & 6.0378 & -5.7248 & 1.1645 & non-conflict & non-conflict \\
\hline 16 & 0.7785 & 0.3333 & 1.2157 & 3.7277 & -6.6580 & 0.7182 & non-conflict & non-conflict \\
\hline 17 & 0.6141 & 0.4326 & 3.3268 & 3.1668 & 2.2917 & 3.1469 & non-conflict & non-conflict \\
\hline 18 & 6.9971 & 0.7223 & 2.0167 & 2.9879 & -2.3484 & 2.5189 & non-conflict & non-conflict \\
\hline 19 & 10.9925 & 0.1068 & 2.1653 & 3.9280 & -4.2459 & 1.2833 & non-conflict & non-conflict \\
\hline 20 & 15.5807 & 0.1672 & 1.6016 & 10.3201 & -6.5891 & 0.8821 & non-conflict & non-conflict \\
\hline
\end{tabular}

a)

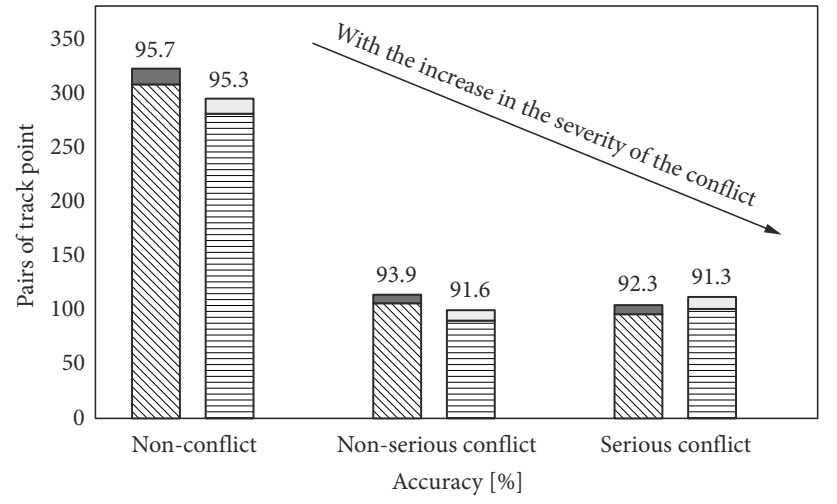

c)

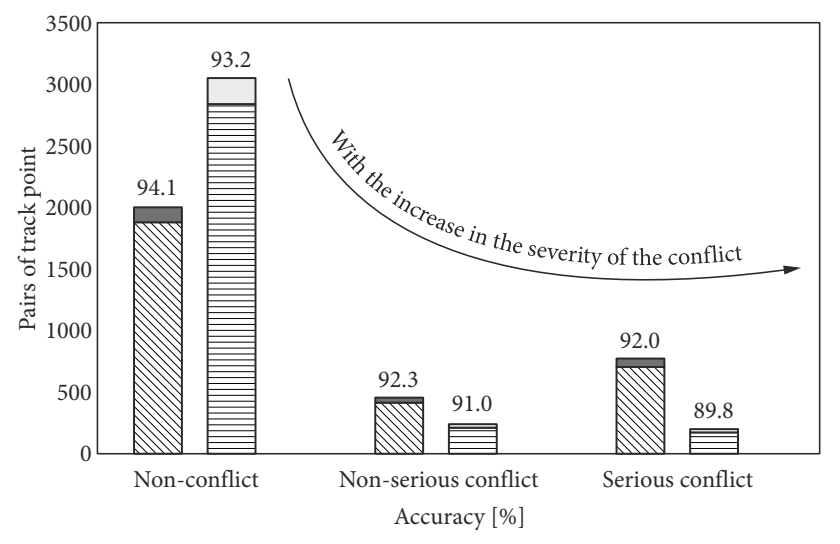

b)

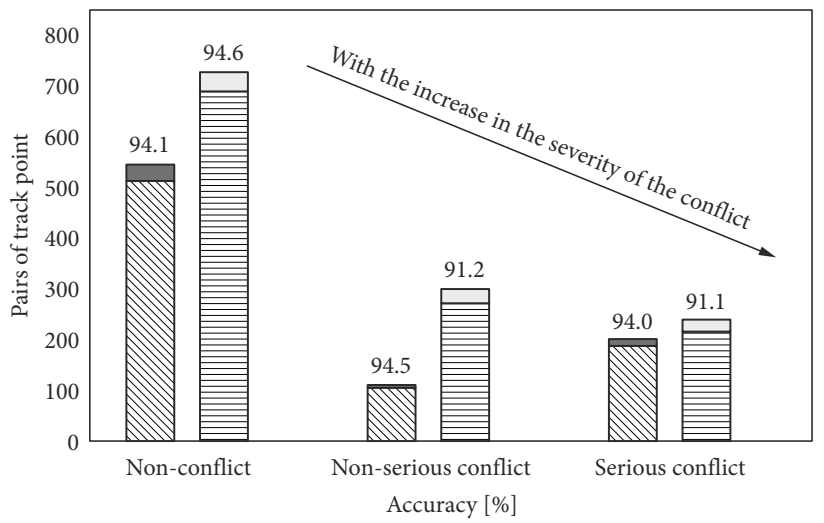

$\mathbb{N}$ the correct pairs of through e-bikes

the pairs of misjudgments for through e-bikes

the correct pairs of left turn e-bikes

the pairs of misjudgments for left turn e-bikes

Figure 7. The test accuracy at different locations: a - Location 4; b - Location 5; c - Location 6 
Table 6. Results for all test samples

\begin{tabular}{|l|c|c|c|c|c|}
\hline \multicolumn{2}{|c|}{ Conflict type } & Non-conflict & Non-serious conflict & Serious conflict & Total \\
\hline \multirow{3}{*}{ Through - through e-bikes } & $N_{p}$ & 2701 & 800 & 996 & 4495 \\
\cline { 2 - 6 } & $N_{t}$ & 2405 & 626 & 813 & 3844 \\
\cline { 2 - 6 } & $N_{d}$ & 2553 & 719 & 869 & 4141 \\
\cline { 2 - 7 } & $N$ & 2864 & 861 & 483 & 4802 \\
\hline \multirow{3}{*}{ Left-turn - left-turn e-bikes } & $N_{p}$ & 3861 & 621 & 367 & 4965 \\
\cline { 2 - 7 } & $N_{t}$ & 3029 & 457 & 418 & 5853 \\
\cline { 2 - 7 } & $N_{d}$ & 3673 & 580 & 532 & 5337 \\
\hline
\end{tabular}

Notes: $N_{p}$ is the number of conflict types identified based on the proposed method; $N_{t}$ is the number of conflict types identified based on TTC indicator; $N_{d}$ is the number of conflict types identified based on deceleration indicator; $N$ is the actual number of conflict types.

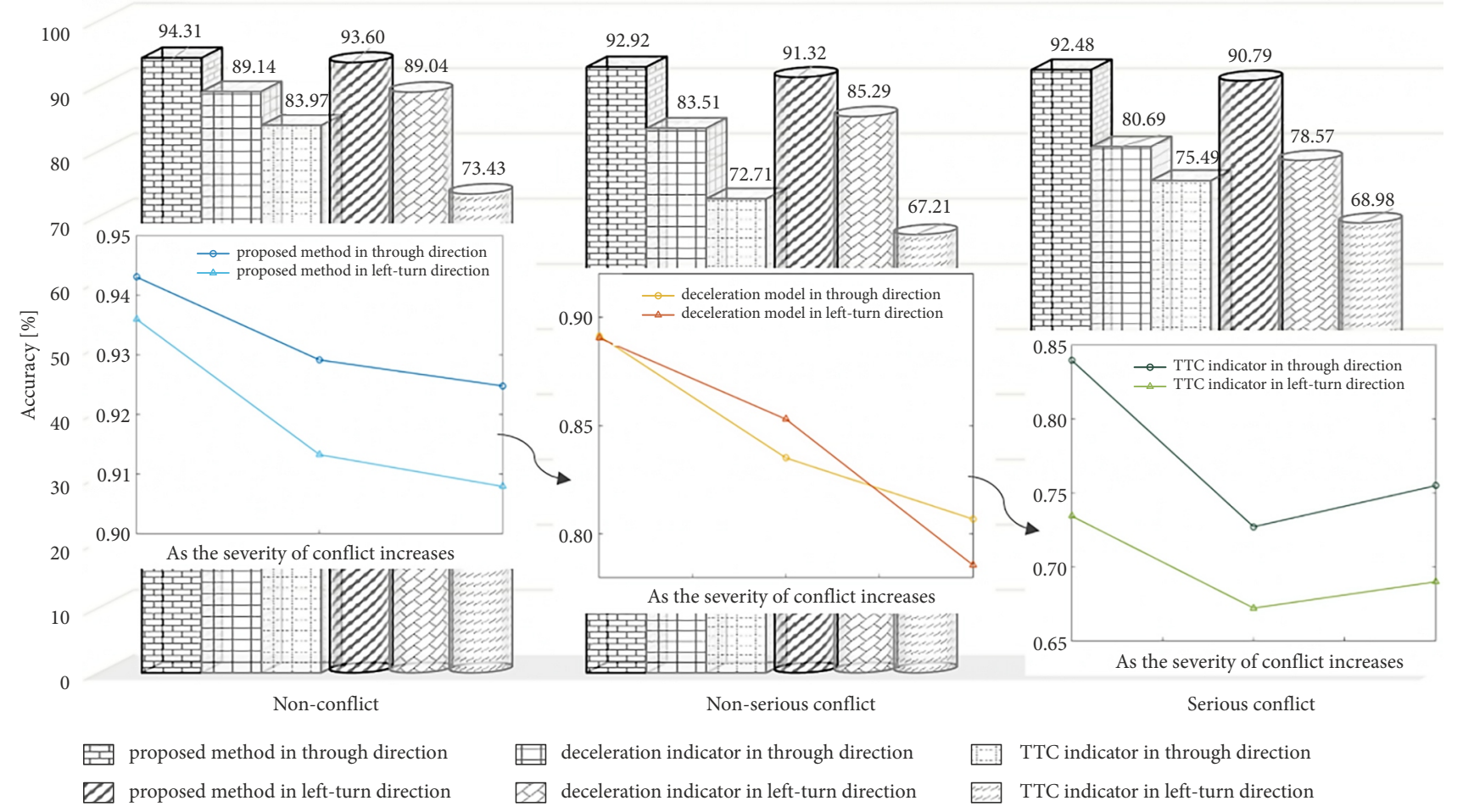

Figure 8. Accuracy of discriminant based on different conflict indicators

Exploring the causes of this phenomenon - on the one hand, TTC is mostly used for discrimination of rear-end conflicts and it may be less suitable for mixed traffic environments with many non-motorized vehicles; on the other hand, deceleration, such an indicator based on evasive behaviour, it can better reflect the conflict between e-bikes, but it can only quantify the magnitude of deceleration action and other aspects cannot be reflected. The identification indicators and method proposed in paper comprehensively consider the influence of space and time, so they can reflect the conflicts between e-bikes more effectively. Combining the above analysis, the proposed method can divide different types of conflict between e-bikes accurately and effectively. Its rationality and credibility are higher.

\subsection{Sensitivity analysis}

To further test the discriminant effect of multi-variable conflict indicator, the paper chooses ROC curve to analyse the sensitivity of $\triangle F P E T, \Delta L$ and $\Delta V_{x d}$. The specific analysis results are shown in Table 7 and Figure 9.

The results show: In through e-bikes, $\Delta V_{x d}$ plays important influence on the test results of non-conflict and non-serious conflict, $\triangle F P E T$ plays important influence on the test results of serious conflict; in left-turn e-bikes, $\Delta L$ plays important influence on the test results of nonconflict and serious conflict, $\Delta V_{x d}$ plays important influence on the test results of non-serious conflict. Meantime, the value of AUC is all above 0.7 and the significance is less than or equal to 0.05 . This indicates that the test has statistical significance and its accuracy is high. 
Table 7. Sensitivity analysis results of different variables

\begin{tabular}{|l|l|c|c|c|c|c|c|}
\hline \multirow{3}{*}{ Test variable } & \multirow{2}{*}{ Test indicator } & \multicolumn{3}{|c|}{ Through - through e-bikes } & \multicolumn{3}{c|}{ Left-turn - left-turn e-bikes } \\
\cline { 3 - 8 } & & Non-conflict & $\begin{array}{c}\text { Non-serious } \\
\text { conflict }\end{array}$ & $\begin{array}{c}\text { Serious } \\
\text { conflict }\end{array}$ & Non-conflict & $\begin{array}{c}\text { Non-serious } \\
\text { conflict }\end{array}$ & $\begin{array}{c}\text { Serious } \\
\text { conflict }\end{array}$ \\
\hline \multirow{2}{*}{$\Delta F P E T[\mathrm{~s}]$} & AUC & 0.53 & 0.52 & 0.76 & 0.52 & 0.62 & 0.54 \\
\cline { 2 - 8 } & gradual significance & 0.58 & 0.75 & 0.04 & 0.64 & 0.78 & 0.74 \\
\hline \multirow{2}{*}{$\Delta L[\mathrm{~m}]$} & AUC & 0.57 & 0.61 & 0.58 & 0.78 & 0.51 & 0.72 \\
\cline { 2 - 8 } & gradual significance & 0.58 & 0.64 & 0.70 & 0.03 & 0.96 & 0.05 \\
\hline \multirow{2}{*}{$\Delta V_{x d}[\mathrm{~m} / \mathrm{s}]$} & AUC & 0.71 & 0.83 & 0.64 & 0.55 & 0.78 & 0.54 \\
\cline { 2 - 8 } & gradual significance & 0.05 & 0.02 & 0.55 & 0.19 & 0.03 & 0.60 \\
\hline
\end{tabular}

a)

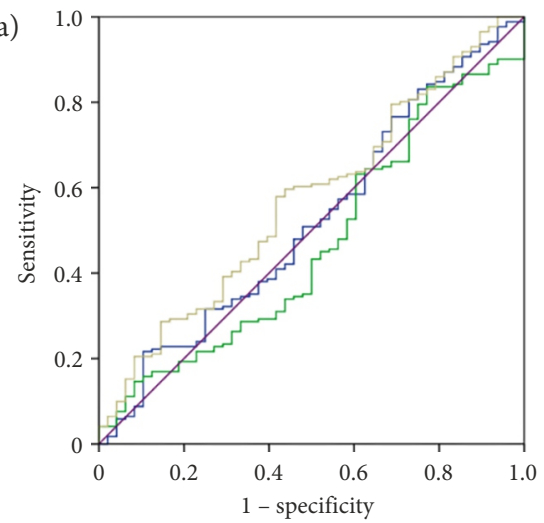

c)

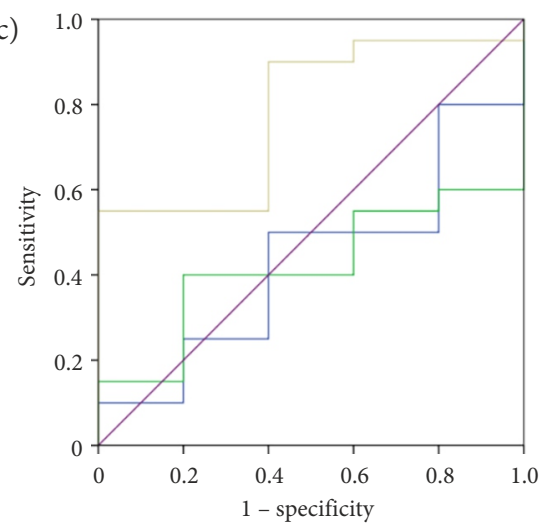

e)

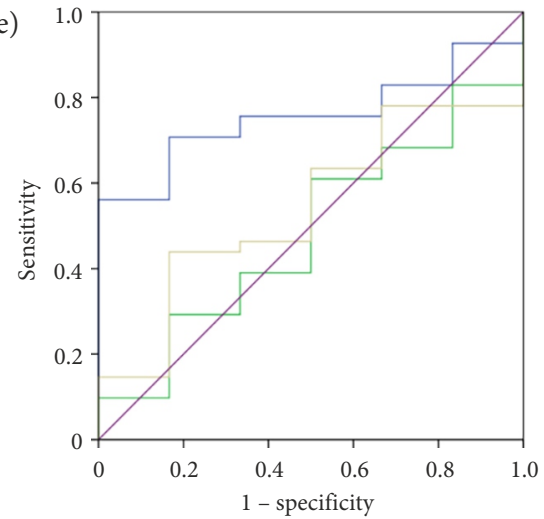

b)

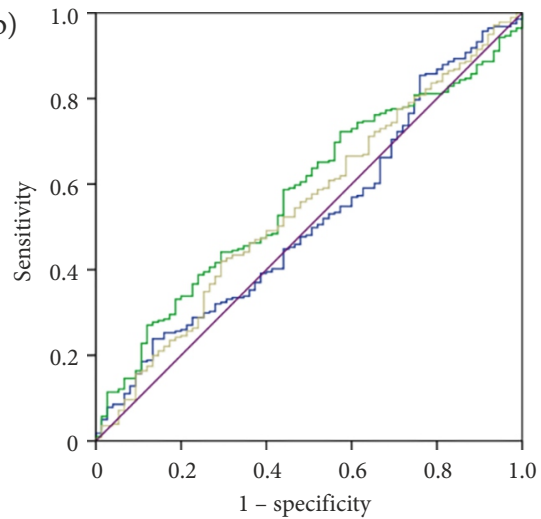

$-\triangle F P E T[\mathrm{~s}]$

$-\Delta L[\mathrm{~m}]$

$-\Delta V_{x d}[\mathrm{~m} / \mathrm{s}]$

— line of reference d)

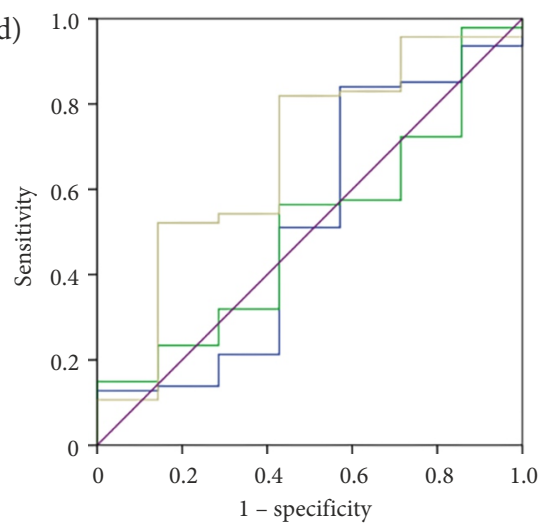

f)

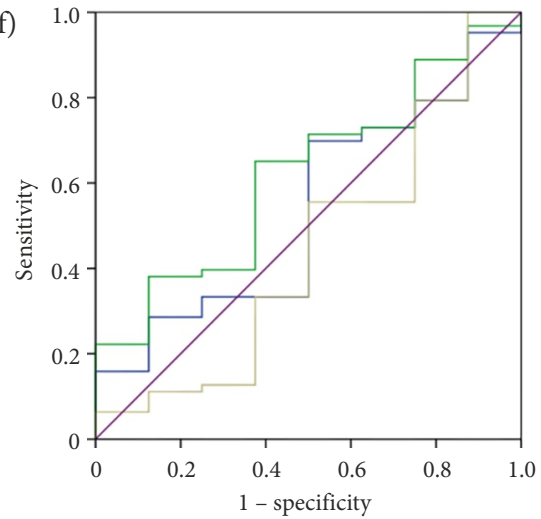

Figure 9. ROC curves of various conflict types in different directions: a - non-conflict in through e-bikes;

$\mathrm{b}$ - non-conflict in left-turn e-bikes; c - non-serious conflict in through e-bikes; $\mathrm{d}$ - non-serious conflict in left-turn e-bikes; $\mathrm{e}$ - serious conflict in through e-bikes; $\mathrm{f}$ - serious conflict in left-turn e-bikes 


\section{Conclusions}

To improve the safety of mixed-traffic flow at the intersection, this paper proposes a novel multi-variable conflict indicator that is based on change of FPET, change of relative speed and change of distance. Then, by utilizing mathematical statistics and cluster discriminant analyses, a new conflict identification method for e-bikes moving in the same direction is built, including conflict existence identification and conflict severity identification. Finally, field data in Suzhou, Guangzhou and Zhengzhou are used to verify the effectiveness of method. Experimental results: in non-conflict, non-serious conflict and serious conflict, the accuracy of through e-bikes are $94.31,92.92,92.48 \%$ respectively; left-turn e-bikes are 93.60, 91.32, 90.79\% respectively; Compared with TTC and deceleration, accuracy of proposed method is the highest. The results show that: multi-variable indicator based on time and space are more suitable for identifying e-bike conflicts than separate space-time approaching indicators; the conflict identification method could satisfy the requirements of e-bike conflict identification.

In addition, other conclusions are drawn during the research:

"» in the type of serious conflict, the range of $\triangle F P E T$ for through e-bikes is $0 \ldots 0.5862 \mathrm{~s}$, and the range of $\triangle F P E T$ for left-turn e-bikes is $0 \ldots 0.7613 \mathrm{~s}$. This result is based on the dataset surveyed in this paper. The threshold range in other traffic environments can also be obtained according to proposed process;

"» in through e-bikes, the most valuable variable in sensitivity analysis is $\Delta V_{x d}$; in left-turn e-bikes, it is $\Delta L$;

"» the setting of dividing strips has significant influence on the number and trend of conflict types.

In general, the proposed multi-variable conflict indicator and conflict identification method provide the theoretical basis for automated conflict detection of mixed traffic flows and scientific management of intersections. In addition, in practical applications, the proposed model can be used to ascertain the location of conflict zone, guide the direction of traffic flow, determine the safe optimization sequence of different traffic flow directions and intersection types (including intersection organization and channelization), and thus road safety can be improved. Moreover, by the statistical analysis of actual data, this study chooses the mean of critical $\triangle F P E T$ as marginal value of serious conflict. However, this choice method is limited by the amount of data and may result in the deviation from marginal value, so finding appropriate settings of critical $\triangle F P E T$ is an important and challenging issue.

\section{Funding}

This work was supported by:

"» the National Natural Science Foundation (China): $A$ Mechanism Study on the Mixed Traffic Flow Based on Full Time and Space Information at Intersections under Grant No 51278220;
"» the Jilin Provincial Science and Technology Development Project (China): Urban Traffic Intelligent Control Strategy and Method Based on Dig Data under Grant No 20180101063JC.

\section{Author contributions}

Zhaowei $Q u$ and Yuhong Gao conceived the study and were responsible for the design and development of the data analysis.

Xianmin Song, Yingji Xia and Yuhong Gao were responsible for data collection and analysis.

Lin Ma and Ronghan Yao were responsible for data interpretation.

Yuhong Gao wrote the first draft of the paper.

\section{Disclosure statement}

This paper does not have any competing financial, professional, or personal interests from other parties.

\section{References}

Alhajyaseen, W. K. M. 2014. The development of conflict index for the safety assessment of intersections considering crash probability and severity, Procedia Computer Science 32: 364371. https://doi.org/10.1016/j.procs.2014.05.436

Alhajyaseen, W. K. M. 2015. The integration of conflict probability and severity for the safety assessment of intersections, Arabian Journal for Science and Engineering 40(2): 421-430. https://doi.org/10.1007/s13369-014-1553-1

Allen, B. L.; Shin, B. T.; Cooper, P. J. 1978. Analysis of traffic conflicts and collisions, Transportation Research Record 667: 67-74.

Amundsen, F. H. 1977. Proceedings from the first Workshop on Traffic Conflicts. September 1977, Oslo, Norway. 138 p.

Autey, J.; Sayed, T.; Zaki, M. H. 2012. Safety evaluation of rightturn smart channels using automated traffic conflict analysis, Accident Analysis \& Prevention 45: 120-130. https://doi.org/10.1016/j.aap.2011.11.015

Bai, L.; Liu, P.; Chen, Y.; Zhang, X.; Wang, W. 2013. Comparative analysis of the safety effects of electric bikes at signalized intersections, Transportation Research Part D: Transport and Environment 20: 48-54. https://doi.org/10.1016/j.trd.2013.02.001

Behbahani, H.; Nadimi, N.; Alenoori, H.; Sayadi, M. 2014. Developing a new surrogate safety indicator based on motion equations, Promet - Traffic \& Transportation 26(5): 371-381. https://doi.org/10.7307/ptt.v26i5.1388

Cherry, C.; Cervero, R. 2007. Use characteristics and mode choice behavior of electric bike users in China, Transport Policy 14(3): 247-257. https://doi.org/10.1016/j.tranpol.2007.02.005

Dozza, M.; Bianchi Piccinini, G. F.; Werneke, J. 2016. Using naturalistic data to assess e-cyclist behavior, Transportation Research Part F: Traffic Psychology and Behaviour 41: 217-226. https://doi.org/10.1016/j.trf.2015.04.003

Guo, Y.; Liu, P.; Bai, L.; Xu, C.; Chen, J. 2014. Red light running behavior of electric bicycles at signalized intersections in China, Transportation Research Record: Journal of the Transportation Research Board 2468: 28-37. https://doi.org/10.3141/2468-04 
Hayward, J. C. 1972. Near-miss determination through use of a scale of danger, Highway Research Record 384: 24-34.

Hyden, C. 1987. The development of a method for traffic safety evaluation: the Swedish traffic conflicts technique, Bulletin Lund Institute of Technology 70: 1-57.

Ismail, K.; Sayed, T.; Saunier, N. 2011. Methodologies for aggregating indicators of traffic conflict, Transportation Research Record: Journal of the Transportation Research Board 2237: 10-19. https://doi.org/10.3141/2237-02

Kim, J.-K.; Kim, S.; Ulfarsson, G. F.; Porrello, L. A. 2007. Bicyclist injury severities in bicycle-motor vehicle accidents, Accident Analysis \& Prevention 39(2): 238-251.

https://doi.org/10.1016/j.aap.2006.07.002

Langford, B. C.; Chen, J.; Cherry, C. R. 2015. Risky riding: naturalistic methods comparing safety behavior from conventional bicycle riders and electric bike riders, Accident Analysis \& Prevention 82: 220-226. https://doi.org/10.1016/j.aap.2015.05.016

Laureshyn, A.; De Ceunynck, T.; Karlsson, C.; Svensson, Å.; Daniels, S. 2017. In search of the severity dimension of traffic events: extended delta-V as a traffic conflict indicator, Accident Analysis \& Prevention 98: 46-56. https://doi.org/10.1016/j.aap.2016.09.026

MIIT. 2018. Safety Technical Specification for Electric Bicycle. Ministry of Industry and Information Technology (MIIT) of the People's Republic of China. Available from Internet: http://www.miit.gov.cn (in Chinese).

Minikel, E. 2012. Cyclist safety on bicycle boulevards and parallel arterial routes in Berkeley, California, Accident Analysis \& Prevention 45: 241-247. https://doi.org/10.1016/j.aap.2011.07.009

Ning, J.; Zhang, L.; Zhang, D.; Wu, C. 2012. Robust mean-shift tracking with corrected background-weighted histogram, IET Computer Vision 6(1): 62-69.

https://doi.org/10.1049/iet-cvi.2009.0075

Pai, C.-W.; Jou, R.-C. 2014. Cyclists' red-light running behaviours: An examination of risk-taking, opportunistic, and law-obeying behaviours, Accident Analysis \& Prevention 62: 191-198. https://doi.org/10.1016/j.aap.2013.09.008

Räsänen, M.; Summala, H. 1998. Attention and expectation problems in bicycle-car collisions: an in-depth study, Accident Analysis \& Prevention 30(5): 657-666.

https://doi.org/10.1016/s0001-4575(98)00007-4

Saccomanno, F. F.; Cunto, F.; Guido, G.; Vitale, A. 2008. Comparing safety at signalized intersections and roundabouts using simulated rear-end conflicts, Transportation Research Record: Journal of the Transportation Research Board 2078: 90-95. https://doi.org/10.3141/2078-12

Sayed, T.; Zaki, M. H.; Autey, J. 2013. Automated safety diagnosis of vehicle-bicycle interactions using computer vision analysis, Safety Science 59: 163-172.

https://doi.org/10.1016/j.ssci.2013.05.009

Sharizli, A. A.; Rahizar, R.; Karim, M. R.; Saifizul, A. A. 2015. New method for distance-based close following safety indicator, Traffic Injury Prevention 16(2): 190-195.

https://doi.org/10.1080/15389588.2014.921913

Silvano, A. P.; Koutsopoulos, H. N.; Ma, X. 2016. Analysis of vehicle-bicycle interactions at unsignalized crossings: A probabilistic approach and application, Accident Analysis \& Prevention 97: 38-48. https://doi.org/10.1016/j.aap.2016.08.016
Tageldin, A.; Sayed, T.; Wang, X. 2015. Can time proximity measures be used as safety indicators in all driving cultures? Case study of motorcycle safety in China, Transportation Research Record: Journal of the Transportation Research Board 2520: 165-174. https://doi.org/10.3141/2520-19

Wang, Y.; Nihan, N. L. 2004. Estimating the risk of collisions between bicycles and motor vehicles at signalized intersections, Accident Analysis \& Prevention 36(3): 313-321. https://doi.org/10.1016/s0001-4575(03)00009-5

Wu, C.; Yao, L.; Zhang, K. 2012. The red-light running behavior of electric bike riders and cyclists at urban intersections in China: an observational study, Accident Analysis \& Prevention 49: 186-192. https://doi.org/10.1016/j.aap.2011.06.001

Wu, Y.; Lu, J.; Chen, H.; Wan, Q. 2016. Modeling the frequency of cyclists' red-light running behavior using Bayesian PG model and PLN model, Discrete Dynamics in Nature and Society 2016: 2593698. https://doi.org/10.1155/2016/2593698

Xu, C.; Yang, Y.; Jin, S.; Qu, Z.; Hou, L. 2016. Potential risk and its influencing factors for separated bicycle paths, Accident Analysis \& Prevention 87: 59-67. https://doi.org/10.1016/j.aap.2015.11.014

Yang, H.; Ozbay, K. 2011. Estimation of traffic conflict risk for merging vehicles on highway merge section, Transportation Research Record: Journal of the Transportation Research Board 2236: 58-65. https://doi.org/10.3141/2236-07 